\title{
ADERÊNCIA DAS DEMONSTRAÇÕES CONTÁBEIS DOS FUNDOS DE PENSÃO DO BRASIL AOS PADRÕES CONTÁBEIS INTERNACIONAIS: UMA ANÁLISE COMPARATIVA À LUZ DA IAS 26 *1
}

\author{
GRIP OF FINANCIAL STATEMENTS OF PENSION FUNDS IN \\ BRAZIL TO INTERNATIONAL ACCOUNTING STANDARDS: \\ A COMPARATIVE ANALYSIS IN THE LIGHT OF IAS 26 \\ Roswelton Anjos de Paula ${ }^{2}$ \\ Graduado em Ciências Contábeis pela UnB \\ roswelton@gmail.com \\ Diana Vaz de Lima \\ Doutora em Ciências Contábeis pelo Programa Multiinstitucional da UnB/UFPB/UFRN \\ Professor da Universidade de Brasília \\ diana lima@unb.br
}

\section{RESUMO}

Apesar de o processo de convergência aos padrões internacionais provocar discussões nos vários ramos da Contabilidade, no Brasil os fundos de pensão devem observar um padrão contábil próprio, respeitando a independência patrimonial de todos os planos de benefícios dos fundos de pensão e identificando, separadamente, os planos previdenciais e assistenciais administrados pelas entidades fechadas de previdência complementar (EFPC). Com o intuito de verificar em que medida a elaboração das demonstrações contábeis das EFPC se encontra aderente aos padrões contábeis internacionais, foi efetuada uma análise comparativa entre os elementos que compõem as estruturas da Demonstração da Mutação do Ativo Líquido (DMAL), da Demonstração do Ativo Líquido (DAL) e da Demonstração das Obrigações Atuariais do Plano de Benefícios (DOAP), definidas pelo padrão próprio brasileiro, e os elementos estabelecidos pela IAS 26 - Accounting and Reporting by Retirement Benefit Plans, que se aplica às demonstrações contábeis dos planos de benefícios, relatando e fornecendo informações aos participantes sobre os recursos e os benefícios do plano ao longo do tempo. Trata-se de um estudo de natureza exploratória, com abordagem qualitativa e coleta de dados realizada de forma essencialmente documental. A justificativa para o estudo está na percepção de que o desenvolvimento de um padrão próprio pode comprometer a inserção da Contabilidade dos fundos de pensão do Brasil nas melhores práticas internacionais, e inibir a participação de eventuais investidores na capitalização desses fundos. Os resultados mostram que as estruturas dos elementos que compõem as demonstrações contábeis desses fundos se encontram, em sua maior parte, aderentes ao disposto na IAS 26, sendo observadas, contudo, divergências de

\footnotetext{
* Artigo apresentado no XI Congresso USP de Iniciação Científica, São Paulo/SP, entre 21 e 23 de julho de 2014.

${ }^{1}$ Artigo recebido em: 30/07/2014. Revisado por pares em: 10/08/2014. Recomendado para publicação em: 20/08/2014 por Orleans Silva Martins (Editor Geral). Publicado em: 31/08/2014. Organização responsável pelo periódico: UFPB.

${ }^{2}$ Endereço: Universidade de Brasília, Campus Darci Ribeiro, FACE, Salas B1-02, Asa Norte, CEP 70.910-900, Brasília/DF. DOI: $\underline{\text { http://dx.doi.org/10.18405/recfin20140205 }}$
} 
caráter formal nas estruturas das demonstrações contábeis e na mensuração a valor justo dos investimentos, passíveis de serem alinhadas.

Palavras-chave: Fundos de Pensão. Demonstrações Contábeis. IAS 26.

\section{ABSTRACT}

Although the process of convergence to international standards provoke discussion in the various branches of accounting in Brazil pension funds must observe proper accounting standards, respecting the independence of all equity benefit plans pension funds and identifying separately the plans pension and assistance given by the closed private pension entities (CVET). In order to ascertain to what extent the preparation of financial statements of CVET is found adhering to international accounting standards, comparative analysis was performed between the elements that make up the structure of the Statement of Changes in Net Assets (DMAL), the Statement of Assets net (DAL) and the Statement of Actuarial Liabilities benefit Plan (DOAP) defined by the Brazilian standard itself, and the elements established by IAS 26 - accounting and Reporting by Retirement benefit plans, which applies to financial statements benefit plans, reporting and providing information to participants about the features and benefits of the plan over time. It is the study of an exploratory nature, with approach qualitative study and data collection performed essentially documentary form. The rationale for the study is the realization that the development of a standard itself may compromise the inclusion of accounts of pension funds in Brazil on international best practices, and inhibit the participation of potential investors in the capitalization of these funds. The results show that the structure of the elements that comprise the financial statements of the pension funds in Brazil is, for the most part, adhered to the provisions of IAS 26, however, differences were observed in the structure of formal character of the financial statements and in measuring the fair value of investments, which can be aligned.

Keywords: Pension Funds. Financial Statements. IAS 26.

\section{INTRODUÇÃO}

O regime de previdência privada é operado pelas entidades de previdência complementar e tem como objetivo principal instituir e executar planos de benefícios de caráter previdenciário. Entidades Fechadas de Previdência Complementar (EFPC), também conhecidas como fundos de pensão, são organizações sem fins lucrativos que administram os fundos previdenciários dos funcionários de uma empresa patrocinadora, de várias empresas ou de instituidores.

A discussão sobre a convergência aos padrões contábeis internacionais nos vários ramos da Ciência Contábil, entre eles a previdência tem se tornado assunto relevante. No Brasil, coube ao Comitê de Procedimentos Contábeis (CPC) a responsabilidade de emitir pronunciamentos contábeis de acordo com as normas do International Accounting Standards Board - IASB (TRINDADE, 2010). O IASB tem como compromisso principal desenvolver um modelo único de normas contábeis internacionais, de alta qualidade, que requeiram transparência e comparabilidade na elaboração de demonstrações contábeis e que atendam ao público interessado, seja ele composto de investidores, administradores, analistas, pesquisadores ou quaisquer outro usuário.

Dentre os padrões desenvolvidos pelo IASB, destaca-se a IAS 26 - Accounting and Reporting by Retirement Benefit Plans que se aplica às demonstrações contábeis dos planos de benefícios, relatando e fornecendo informações aos participantes sobre os recursos e os benefícios do plano ao longo do tempo (MUTHUPANDIAN, 2010).

Considerando que o Brasil vem desenvolvendo ao longo dos anos um padrão contábil próprio no âmbito dos fundos de pensão e que existe uma discussão nos vários ramos da Contabilidade brasileira para a adoção dos padrões contábeis internacionais, o presente estudo traz a seguinte questão de pesquisa: em que medida a elaboração das demonstrações contábeis das entidades 
fechadas de previdência complementar encontra-se aderente aos padrões contábeis internacionais, em particular à IAS 26?

Nesse sentido, o presente estudo tem como objetivo verificar a aderência das demonstrações contábeis dos fundos de pensão do Brasil aos padrões contábeis internacionais, tendo como base a IAS 26, por meio de uma análise comparativa entre os elementos que compõem as estruturas da Demonstração da Mutação do Ativo Líquido (DMAL), da Demonstração do Ativo Líquido (DAL) e da Demonstração das Obrigações Atuariais do Plano de Benefícios (DOAP), definidas pelo padrão próprio brasileiro, e os elementos estabelecidos pela IAS 26.

De acordo com o método de desenvolvimento deste trabalho ele é um estudo de natureza exploratória, com abordagem de pesquisa do tipo qualitativa e com coleta de dados realizada de forma essencialmente documental. Assim, além desta introdução, este estudo encontra-se estruturado em mais quatro seções. Na segunda seção é abordado o referencial normativo aplicado aos fundos de pensão. Na terceira são apresentados os requisitos mínimos exigidos para a apresentação de uma demonstração financeira pela IAS 26 e os elementos exigidos pelo padrão próprio brasileiro. Na quarta é efetuada uma análise comparativa entre os elementos exigidos pelo padrão brasileiro e pela IAS 26. E a quinta seção traz as considerações finais do estudo.

\section{REFERENCIAL NORMATIVO}

A previdência privada ou previdência complementar busca acumular recursos financeiros com a capacidade de proporcionar no futuro uma aposentadoria, mantendo os mesmos poderes de compra e as mesmas condições socioeconômicas que o aposentado tinha quando estava em plena capacidade produtiva (COELHO; CAMARGOS, 2012). Assim, a previdência complementar é uma forma de poupança que visa garantir que o aposentado não sofra uma redução em seu salário, garantindo o futuro e a segurança da família (TRINDADE, 2010).

As Entidades Fechadas de Previdência Complementar (EFPC), também conhecidas como fundos de pensão, são instituições sem fins lucrativos que administram planos previdenciários para empregados de uma empresa, de um conjunto de empresas ou grupo de empresas, de servidores da União, do Distrito Federal ou dos Municípios, entes esses denominados patrocinadores, e dos associados ou membros de pessoas jurídicas de caráter profissional, classistas ou setoriais denominadas instituidoras (ALVES, 2011). Em sua essência, o objetivo central de um fundo de pensão é proteger o funcionário e sua família durante seu período de inatividade (morte ou invalidez) e após o período de sua aposentadoria (MATHEUS, 2012).

Para Trindade (2010), um fundo de pensão existe sob as mais variadas formas e opções de participação. Segundo o pesquisador, não é preciso estar ligado a uma empresa pública ou privada para ingressar em um sistema de aposentadoria complementar fechada, basta fazer parte de um plano associativo, que são aqueles instituídos por sindicatos, associações, cooperativas ou quaisquer outras organizações representativas de categorias de trabalhadores ou profissões regulamentadas.

\subsection{Padrão Brasileiro de Previdência Complementar}

Em janeiro de 2010, considerando a necessidade de regulamentação do segmento de entidades fechadas de previdência complementar com norma contábil específica, a pedido da PREVIC, autarquia federal vinculada ao Ministério da Previdência Social com as funções de fiscalização e de supervisão das atividades das EFPC, o Conselho Federal de Contabilidade (CFC, 2010) editou a Resolução CFC no 1.272 .

A Resolução CFC nำ 1.272/2010 estabeleceu critérios e procedimentos específicos para estruturação das demonstrações contábeis, para registro das operações e variações patrimoniais, bem 
como para o conteúdo mínimo das notas explicativas a serem adotadas pelas EFPC, tendo como base os normativos contábeis já instituídos no âmbito das EFPC.

De acordo com o item 4 da Resolução CFC no 1.272/2010, a estrutura da planificação contábil padrão estabelecida para as EFPC brasileiras reflete o ciclo operacional de longo prazo da sua atividade, de forma que a apresentação de ativos e passivos, observadas as gestões previdencial, assistencial e administrativa, bem como os investimentos, proporcione informações mais adequadas, confiáveis e relevantes do que a apresentação em "circulante" e "não circulante" disposta no padrão contábil internacional.

Em dezembro de 2011, guardando os mesmos fundamentos contemplados anteriormente nas normas já observadas pelas EFPC e pela Resolução CFC no 1.272/2010, o Conselho Nacional de Previdência Complementar (CNPC) editou a Resolução CNPC n॰ 8, dispondo sobre os novos procedimentos contábeis a serem observados e revogando a resolução anterior sobre o mesmo assunto. No caso das EFPC que operam planos de assistência à saúde, adicionalmente devem ser seguidas as instruções e a planificação contábil estabelecida pela Agência Nacional de Saúde Suplemen$\operatorname{tar}$ (ANS).

A Resolução CNPC n॰ 8/2011 é acompanhada de três anexos, que tratam da planificação contábil padrão, dos modelos e instruções de preenchimento das demonstrações contábeis, e das normas gerais de procedimentos contábeis, com aderência ao disposto na Resolução CFC $\mathrm{n}^{\mathrm{o}}$ 1.272/2010. O art. 3॰ da Resolução CNPC n॰ 8/2011 confere autorização para a PREVIC editar instruções a ela complementares, inclusive estabelecer procedimentos contábeis específicos, alterar, incluir e excluir rubricas da planificação contábil padrão e disciplinar a forma, o meio e a periodicidade para envio das demonstrações contábeis, e recepcionou a Instrução Normativa SPC $n^{\circ}$ 34/2009 por ela emitida, onde são definidas as formas, os meios e os períodos que serão observados por cada EFPC no envio de suas demonstrações contábeis aos órgãos de fiscalização.

As normas gerais de procedimentos contábeis estabelecidos pela Resolução CNPC n ${ }^{\circ}$ 8/2011 têm como objetivo propor a homogeneização dos registros e fatos contábeis relacionados a todas as entidades. Assim, a Contabilidade deverá ser desenvolvida considerando a autonomia patrimonial dos planos, reconhecendo separadamente todos os planos previdenciais, assistenciais e o plano de gestão administrativa geridos pela entidade, assegurando informações com maior transparência e consistência. Desta forma, os demonstrativos contábeis deverão elaborados por plano de benefícios, configurando as informações de forma mais transparente e consistente, caracterizando cada uma das atividades realizadas.

\subsection{Padrão IASB: IAS 26}

Em janeiro de 1987, o International Accounting Standards Committee (IASC) emitiu a IAS 26 Accounting and Reporting by Retirement Benefit Plans, operacionalizando as demonstrações contábeis de todos os benefício de aposentadoria dos fundos de pensão. Em abril de 2001, o IASB assumiu todas as responsabilidades do International Accounting Standards Committee (IASC) e decidiu que todas as normas e interpretações emitidas anteriormente continuariam sendo aplicadas até que houvesse alguma alteração ou a devida norma fosse revogada, mantendo na integra o disposto na IAS 26.

De acordo com a IAS 26, os fundos de pensão são caracterizados como sendo planos de Contribuição Definida (CD) ou de Benefício Definido (BD). No caso dos planos CD, quanto ao nível de benefícios que serão pagos aos participantes do plano, a determinação é dada pelo número de contribuições pagas pelo empregador dos participantes, os participantes em si, ou ambos, em conjunto com a rentabilidade dos ativos de investimentos.

Os planos BD, por sua vez, se comprometem a pagar benefícios com frequência predeterminada por formulas que envolve fatores como anos de serviço e nível salarial na época da apo- 
sentadoria, sem considerar se esses planos possuem ativos suficientes ou não para honrar seus compromissos futuros. Assim, a responsabilidade final pelo pagamento (que pode ser garantido por uma empresa que opera seguros, governo ou outra entidade, dependendo das leis e costumes de cada país) continua sendo do empregador. Em circunstâncias extraordinárias, o fundo de pensão pode conter características de ambos os tipos de plano. A IAS 26 classifica esses planos híbridos como planos de benefício definido (IFRS, 2012).

A IAS 26 estabelece ainda princípios para a contabilização e a composição mínima dos relatórios que deverão ser apresentados pelas entidades fechadas de previdência complementar, com o objetivo de elencar todos os princípios básicos para a divulgação dos relatórios emitidos pelos fundos de pensão. Assim, todas as entidades deverão incluir em seus relatórios contábeis uma demonstração de alterações dos ativos líquidos por plano de benefícios, um resumo das principais práticas contábeis e uma descrição de cada plano com as devidos efeitos das alterações, caso tenha ocorrido durante o período (IFRS, 2012).

Portanto, a IAS 26 deve ser aplicada na elaboração das demonstrações financeiras dos planos de benefícios de aposentadoria, relatando a todos os participantes como um grupo, e especificamente não se tratando de relatórios para as pessoas sobre os seus benefícios de aposentadoria. Ressalta-se que a IAS 26 não divulga outras formas de benefícios de emprego, tais como as rescisões de emprego, acordos de retribuição diferida, benefícios aos que deixam planos de aposentadoria antecipada especial ou redundância, saúde e bem-estar ou planos de bônus.

\section{OS PADRÕES E AS ESTRUTURAS DOS BALANÇOS}

\subsection{Estruturas das Demonstrações Exigidas pelo Padrão Brasileiro}

No Brasil, a Contabilidade das EFPC é elaborada respeitando a independência patrimonial de todos os planos de benefícios dos fundos de pensão, identificando, separadamente, os planos previdenciais e os assistenciais administrados, bem como o plano de gestão dos recursos administrativos, procurando assegurar um conjunto de informações consistentes e transparentes.

Conforme o disposto no art. $4^{\circ}$ da Instrução SPC n 34, de 2009, é obrigatória a elaboração mensal dos balancetes dos Planos de Benefícios, do Plano Gestão Administrativa e um balancete consolidando todas as informações da entidade, sendo que essas informações devem ser enviadas até o último dia do mês ao trimestre de "referência". Além dessas obrigações, a entidade deverá enviar para o órgão fiscalizador (PREVIC), no ano subsequente, até o dia 31 de março, o Balanço Patrimonial da entidade, a Demonstração da Mutação do Ativo Líquido, entre outros, sempre mantendo a comparação com o exercício anterior. Assim, nesta etapa do presente estudo serão apresentadas as demonstrações que podem ser relacionadas com a norma internacional IAS 26.

Na estrutura da Demonstração da Mutação do Ativo Líquido (DMAL), o ativo líquido representa o saldo do ativo líquido do plano de benefícios no início do exercício, sendo composto pelas Adições (que representam todos os recursos que contribuíram para o aumento do ativo líquido do plano de benefícios durante o exercício); Deduções (todos os recursos que contribuíram para a diminuição do ativo líquido do plano de benefícios durante o exercício); Acréscimo/Decréscimo no Ativo Líquido (a variação anual no Ativo Líquido do plano de benefícios); Operações Transitórias (representados pela variação do ativo líquido do plano em função das operações de incorporação, fusão, cisão e transferência de gerenciamento); Ativo Líquido do final do exercício (representa o saldo do ativo líquido do plano de benefícios no final do exercício); e Fundos não Previdenciais (que representa o saldo dos fundos não previdenciais do plano de benefícios no final do exercício), conforme Quadro 1. 
Quadro 1 - Demonstração da Mutação do Ativo Líquido - DMAL - (Em R\$ mil).

\begin{tabular}{|l|l|l|l|}
\hline \multicolumn{1}{|c|}{ Descrição } & Exercício atual & Exercício anterior & Variação \% \\
\hline A) Ativo líquido - início do exercício & & & \\
\hline 1. Adições & & & \\
(+) Contribuições & & \\
(+) Resultado positivo dos investimentos - gestão previdencial & & \\
(+) Reversão de contingências - gestão previdencial & & & \\
\hline 2. Destinações & & \\
(-) Benefícios & & \\
(-) Resultado negativo dos investimentos - gestão previdêncial & & \\
(-) Constituição de contingências - gestão previdêncial & & \\
(-) Custeio administrativo & & \\
\hline 3. Acréscimo/decréscimo no ativo líquido (1+2) & & \\
(+/-) Provisões matemáticas & & \\
(+/-) Fundos previdenciais & & \\
(+/-) Superávit (déficit) técnico do exercício & & \\
\hline 4. Operações transitórias & & \\
(+/-) Operações transitórias & & & \\
\hline B) Patrimônio social - final do exercício (A+3+4) & & \\
\hline C) Fundos não previdenciais & & \\
\hline (+/-) Fundos administrativos & & \\
\hline
\end{tabular}

Fonte: BRASIL (2012, p. 253).

O papel da Demonstração do Ativo Líquido (DAL), por sua vez, é demonstrar todos os componentes patrimoniais do plano de benefícios, no exercício em referência, e discrimina os saldos dos grupos de contas do ativo (Disponível, Investimentos, entre outros); saldos dos grupos de contas do passivo (Operacional e Contingencial); e saldos dos grupos de contas do patrimônio social, conforme Quadro 2.

Quadro 2 - Demonstração do Ativo Líquido - DAL - (Em R\$ mil).

\begin{tabular}{|l|l|l|l|}
\hline \multicolumn{1}{|c|}{ Descrição } & Exercício Atual & Exercício Anterior & Variação \% \\
\hline $\begin{array}{l}\text { 1. Ativos } \\
\text { Disponível }\end{array}$ & & & \\
Investimento & & & \\
Depósitos judiciais / recursais & & & \\
Outros realizáveis & & & \\
Permanente & & & \\
2. Obrigações & & & \\
Operacional & & & \\
\hline 3. Funtingencial & & & \\
Fundos não previdenciais & & & \\
Fundos dos investimentos & & & \\
\hline 4. Resultados a realizar & & & \\
\hline 5. Ativo líquido (1-2-3-4) & & & \\
Provisóes matemáticas & & & \\
Superávit/déficit técnico & & & \\
Fundos previdenciais & & & \\
\hline
\end{tabular}

Fonte: BRASIL (2012, p. 255).

Nas EFPC do Brasil há ainda a exigência de divulgação em quadro próprio da Demonstração das Obrigações Atuariais do Plano de Benefícios (DOAP), conforme Resolução CNPC n⿳o 8/2011. Com o intuito de evidenciar as alterações do patrimônio de cobertura do plano, a DOAP discrimina o saldo do patrimônio de cobertura do plano no início do exercício; os saldos detalhados das provisões matemáticas de benefícios concedidos, as provisões matemáticas de benefícios a 
conceder e provisões matemáticas a constituir; e os saldos detalhados do equilíbrio técnico, em resultados realizados e resultados a realizar, conforme Quadro 3.

Quadro 3 - Demonstração das Obrigações Atuariais do Plano de Benefícios - DOAP - (Em R\$ mil).

\begin{tabular}{|l|l|l|l|}
\hline \multicolumn{1}{|c|}{ Descrição } & Exercício Atual & Exercício Anterior & Variação \% \\
\hline Patrimônio de Cobertura do Plano (1 + 2) & & & \\
\hline 1. Provisões Matemáticas & & & \\
1.1. Benefícios Concedidos & & & \\
1.2. Benefício a Conceder & & & \\
1.3. (-) Provisões matemáticas a constituir & & & \\
\hline 2. Equilíbrio Técnico & & & \\
2.1. Resultados Realizados & & & \\
$\quad$ Superávit técnico acumulado & & & \\
$\quad$ Reserva de contingência & & & \\
Reserva para revisão de plano & & & \\
2.2. Resultados a realizar & & & \\
\hline
\end{tabular}

Fonte: BRASIL (2012, p. 261).

\subsection{A Estrutura das Demonstrações Exigidas pela IAS 26}

De forma detalhada, segundo o disposto na IAS 26, a estrutura de um plano BD difere da abordagem do plano CD, na qual, após a aposentadoria, os trabalhadores recebem os montantes reservados para o pagamento, adicionando ou subtraindo, respectivamente, os lucros ou prejuízos acumulados do investimento, independentemente de quais forem os montantes.

No caso de plano CD, conforme itens 16 e 17 da IAS 26, devem conter: a) demonstração dos ativos líquidos contendo as informações dos benefícios; b) a demonstração das mutações dos ativos líquidos; c) um resumo das principais práticas contábeis adotadas; d) uma descrição do plano e os efeitos de quaisquer mudanças ocorridas no período; e) uma descrição das políticas de custeio do plano. Um exemplo da Demonstração dos Ativos Líquidos Disponíveis para Benefícios de um plano de contribuição definida (CD) é apresentado na Quadro 4.

Quadro 4 - Demonstração do Patrimônio Líquido Disponível para Benefícios.

\begin{tabular}{|c|c|}
\hline Descrição & $€ 0,000$ \\
\hline Renda de Investimento & \\
\hline $\begin{array}{l}\text { Receita de juros } \\
\text { Receita de dividendos } \\
\text { Apreciação (ganho não realizado) no valor justo de investimentos } \\
\text { Renda de investimento total }\end{array}$ & \\
\hline Contribuições para o Plano & \\
\hline $\begin{array}{l}\text { As contribuições do empregador } \\
\text { Contribuições dos empregados } \\
\text { Total de contribuições do plano } \\
\text { Total das adições (valor do ativo líquido) }\end{array}$ & \\
\hline Pagamentos do Plano de Benefícios & \\
\hline $\begin{array}{l}\text { Pensões (anual) } \\
\text { Pagamentos (montante fixo na aposentadoria) } \\
\text { Verbas rescisórias } \\
\text { Permutação do caixa dos benefícios de pensões } \\
\text { Pensões (anual) } \\
\text { Total dos pagamentos dos planos de benefícios } \\
\text { Total das deduções de valor patrimonial líquido }\end{array}$ & \\
\hline Aumento Líquido do Valor Patrimonial & \\
\hline Ativo Líquido Disponível para Benefícios & \\
\hline $\begin{array}{l}\text { Início do ano } \\
\text { Fim do ano }\end{array}$ & \\
\hline
\end{tabular}

Fonte: IFRS (2012). 
As demonstrações exigidas para o plano BD, conforme item 17 da IAS 26, são: a) uma demonstração dos ativos líquidos para atender os benefícios, o valor presente atuarial dos benefícios de aposentadoria prometidos e o superávit ou déficit do período; ou b) uma referência a esta informação em um relatório dos atuários.

Em conformidade com o estabelecido pela IAS 26, itens 18, 19 e 20, os montantes que devem ser pagos como benefícios pós-aposentadoria é determinado por uma fórmula, sendo baseados em ganhos de acordo com os anos de serviços prestados pelos empregados. O fator crucial é que os benefícios são fixos, independentemente da valorização dos ativos reservados para o pagamento dos benefícios. No Quadro 5 é apresentado um exemplo da estrutura da Demonstração do Patrimônio Líquido no plano BD, com a distinção dos benefícios atuariais acumulados e o excesso ou déficit do plano previsto na IAS 26.

Quadro 5 - Demonstração do Patrimônio Líquido Disponível para Benefícios.

\begin{tabular}{|c|c|}
\hline Descrição & $€ 0,000$ \\
\hline 1. Demonstração dos Ativos Líquidos Disponíveis para Benefícios & \\
\hline $\begin{array}{c}\text { Ativos } \\
\end{array}$ & \\
\hline $\begin{array}{l}\text { Investimentos a valor justo } \\
\text { Créditos } \\
\text { Montantes devidos por corretores da bolsa na venda de títulos } \\
\text { Juros corridos } \\
\text { Dividendos a receber } \\
\text { Receber total } \\
\text { Disponível } \\
\text { Total do ativo }\end{array}$ & \\
\hline PASSIVOS & \\
\hline $\begin{array}{l}\text { Contas a pagar } \\
\text { Despesas provisionadas } \\
\text { Total do passivo } \\
\text { Ativo líquido disponível para benefícios }\end{array}$ & \\
\hline 2. Valor Presente Atuarial dos Benefícios Plano Acumuladas & \\
\hline $\begin{array}{l}\text { Benefícios adquiridos } \\
\text { Benefícios a conceder } \\
\text { Total }\end{array}$ & \\
\hline 3. Excesso de Net Asseta Disponíveis para Benefícios mais Presente Atuarial & \\
\hline Valor de benefícios do plano acumuladas & \\
\hline
\end{tabular}

Fonte: IFRS (2012).

No Quadro 6 é apresentado um exemplo da estrutura da Demonstração das Variações Patrimoniais Disponíveis para Benefício, prevista no item 17 da IAS 26, relatando as operações e o desempenho dos investimentos para o período e a posição financeira do plano no final do período.

Outro diferencial da IAS 26 é que a norma determina que as demonstrações contábeis devem conter uma explicação reconciliando o valor presente atuarial da obrigação do plano de benefícios e o valor dos ativos líquidos disponíveis para os benefícios e uma descrição da política para custeamento do plano, devendo os ativos do plano de benefícios ser mensurados pelo valor justo. 
Quadro 6 - Demonstração das Variações Patrimoniais Disponíveis para Benefício.

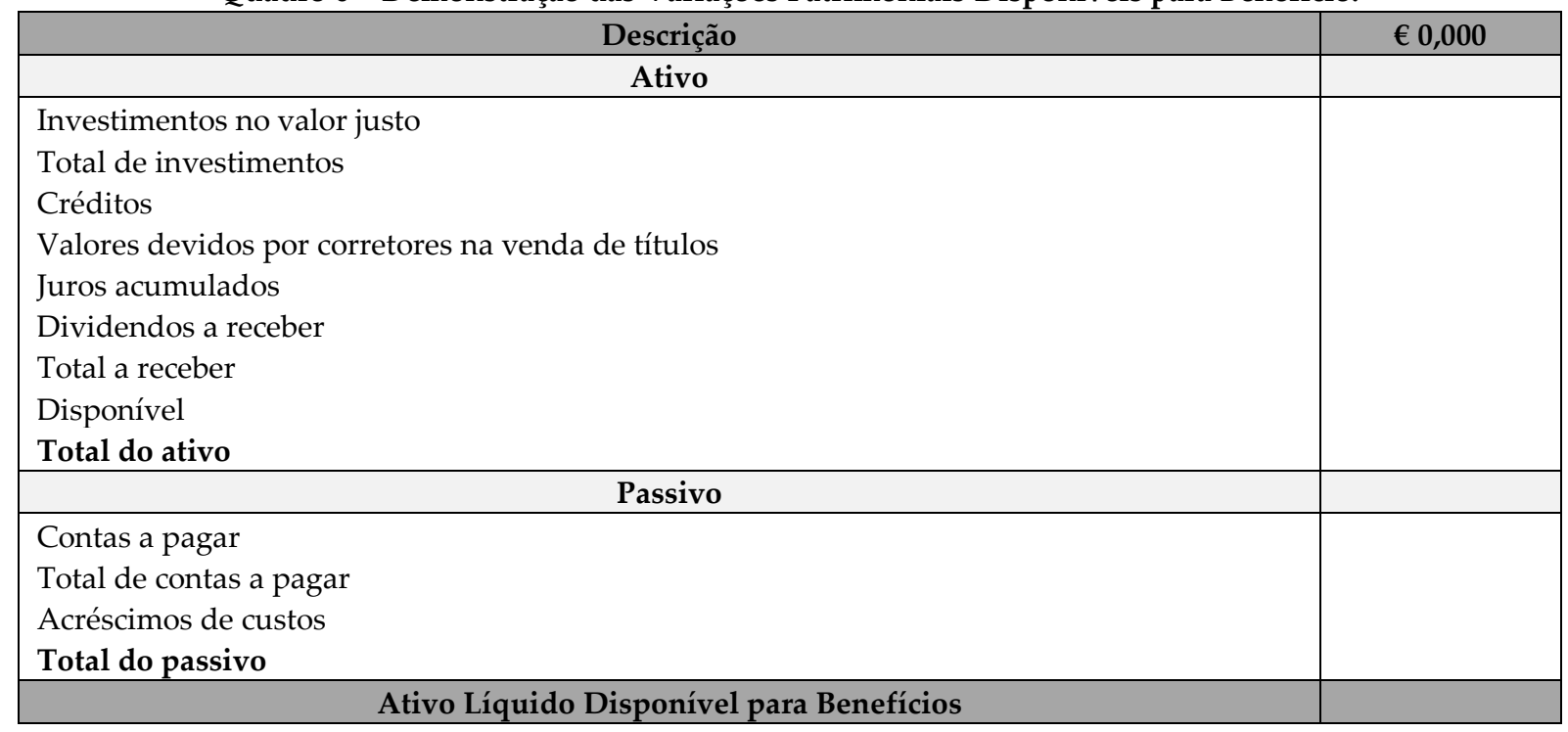

Fonte: IFRS (2012).

\section{ANÁLISE COMPARATIVA: ADERÊNCIA AOS PADRÕES INTERNACIONAIS}

Objetivando verificar a aderência das demonstrações contábeis dos fundos de pensão do Brasil aos padrões contábeis internacionais, tendo como base a IAS 26 - Accounting and Reporting by Retirement Benefit Plans, foi efetuada uma análise comparativa a partir dos elementos que compõem a estrutura da DMAL, da DAL e da DOAP.

Para a Demonstração de Ativos Líquidos Disponíveis para Benefícios, prevista na IAS 26, foram verificados seus principais itens: Investimentos no Valor Justo, Créditos a Receber, Valores devidos por corretores na venda de títulos, Juros acumulados, Dividendos a Receber, Contas a Pagar, Acréscimos de Custos, Ativo Líquido Disponível para Benefícios. Na Demonstração do Patrimônio Líquido Disponível para Benefícios, conforme IAS 26, são analisados, entre outros, os benefícios adquiridos, os benefícios a adquirir e o valor de benefícios do plano acumulado.

E por fim, com relação à estrutura da Demonstração das Variações Patrimoniais Disponíveis para Benefício prevista na IAS 26, será analisado o Resultado Financeiro, Rendimento dos Dividendos, a Apreciação (ganho não realizado) de valores dos investimentos, as Contribuições do empregador e dos empregados, os Pagamentos de Pensões (anual), os pagamentos de indenizações, o aumento do valor patrimonial e o ativo líquido disponíveis para benefícios.

Para verificar se as EFPC brasileiras, objeto do estudo, atendem ao modelo proposto pela IAS 26 - Accounting and Reporting by Retirement Benefit Plans, a análise foi segregada em itens, visando esclarecer as principais semelhanças e diferenças na estrutura das Demonstrações Contábeis. No Quadro 7 é analisada a existência das contas presentes na Demonstração do Patrimônio Líquido Disponível para Benefícios, ou seja, a existência de Investimentos no valor justo, Passivos e Ativos Líquidos Disponíveis para o pagamento de benefícios. No padrão brasileiro, essas informações estão contempladas na DAL.

Além do disposto na IAS 26, as normas brasileiras acrescentam na DAL as Provisões Matemáticas (valor da variação das Reservas a Amortizar dos Planos de Benefícios), o Superávit/Déficit técnico (valor da variação patrimonial para cobertura dos compromissos dos Planos de Benefícios) e os Fundos Previdenciais (valor definido pelo atuário com o objetivo de cobertura dos riscos, oscilações de riscos ou mesmo para alocar recursos destinados a futuras alterações do Plano de Benefícios). 
Quadro 7 - Análise da Demonstração do Patrimônio Líquido Disponíveis para Benefícios Segundo a IAS 26.

\begin{tabular}{|c|c|l|}
\hline IAS 26 & $\begin{array}{c}\text { Demonstração do } \\
\text { Ativo Líquido - DAL } \\
\text { (Padrão Brasileiro) }\end{array}$ & Observações \\
\hline $\begin{array}{c}\text { Investimentos no } \\
\text { valor justo }\end{array}$ & Há divergências & $\begin{array}{l}\text { As EFPC não apresentam na estrutura da DAL o valor justo do investi- } \\
\text { mento apresentado em sua carteira. Dependendo da política de investi- } \\
\text { mentos adotada por cada EFPC, os investimentos podem ser mantidos até } \\
\text { o vencimento ou a mercado, impactando a contabilização. }\end{array}$ \\
\hline Passivo & Há divergências & $\begin{array}{l}\text { Por ser apresentada na forma de fluxo financeiro, não existe a figura do } \\
\text { passivo na DAL. As obrigações do plano de benefícios, com relação ao } \\
\text { ativo líquido disponível, são evidenciadas na forma de Obrigações Opera- } \\
\text { cionais e Contingenciais. }\end{array}$ \\
\hline $\begin{array}{c}\text { Ativo Líquido } \\
\text { Disponível para } \\
\text { benefícios. }\end{array}$ & Não há divergências & $\begin{array}{l}\text { No final da demonstração é apresentada a informação do valor líquido do } \\
\text { Ativo que está disponível para o benefício. }\end{array}$ \\
\hline
\end{tabular}

Fonte: Elaboração Própria.

Ao analisar o Quadro 7, verifica-se que há divergências com relação ao valor justo dos investimentos e a existência da figura do Passivo na demonstração. Os títulos e valores mobiliários, nos quais o plano de benefícios aplicam seus recursos, podem ser marcados a valor de mercado ou contabilizados até o vencimento pela taxa do papel ("marcação na curva"). No Brasil, não existe a obrigatoriedade de marcação dos investimentos a valor justo. As obrigações do plano de benefícios são evidenciadas na forma de obrigações operacionais e contingenciais, sendo a DAL apresentada na forma de fluxo financeiro.

Com relação à Demonstração das Variações Patrimoniais Disponíveis para Benefício, apresentada pela IAS 26, o Quadro 8 analisa a existência do Resultado Financeiro, as Contribuições para o Plano de Benefícios, o Plano de pagamento dos Benefícios, o aumento do Valor Patrimonial e o Ativo Líquido disponível para benefícios. Essas informações estão contempladas na DMAL, exigida pelo padrão brasileiro.

\begin{tabular}{|c|c|c|}
\hline Itens da IAS 26 & $\begin{array}{c}\text { Demonstração da Mutação } \\
\text { do Ativo Líquido - DMAL } \\
\text { (Padrão Brasileiro) }\end{array}$ & Observações \\
\hline $\begin{array}{l}\text { Resultado dos } \\
\text { Investimentos }\end{array}$ & Não há divergências & $\begin{array}{l}\text { O resultado dos investimentos representa uma adição do Ativo } \\
\text { Líquido }\end{array}$ \\
\hline $\begin{array}{l}\text { Contribuições para } \\
\text { o Plano }\end{array}$ & Não há divergências & $\begin{array}{l}\text { As contribuições para os planos de benefícios representa uma } \\
\text { adição do Ativo Líquido }\end{array}$ \\
\hline $\begin{array}{l}\text { Plano de pagamen- } \\
\text { to de benefícios }\end{array}$ & Não há divergências & $\begin{array}{l}\text { Os benefícios representam uma destinação dos Ativos líquidos, } \\
\text { constituindo-se uma dedução dessas variações. }\end{array}$ \\
\hline $\begin{array}{l}\text { Aumento do valor } \\
\text { patrimonial }\end{array}$ & Não há divergências & Representa variação no Ativo Líquido do plano de benefícios. \\
\hline $\begin{array}{l}\text { Ativo líquido dispo- } \\
\text { nível para benefícios }\end{array}$ & Não há divergências & $\begin{array}{l}\text { Na DMAL é o ativo líquido representado pelo Patrimônio So- } \\
\text { cial - Final do Exercício. }\end{array}$ \\
\hline
\end{tabular}

Fonte: Elaboração Própria.

Com relação à Demonstração do Patrimônio Líquido Disponível para Benefícios, apresentada pela IAS 26, o Quadro 9 apresenta as contas contempladas na DOAP, exigida pelo padrão brasileiro, analisando a existência do Valor Presente Atuarial dos Benefícios do Plano e o Excesso dos Ativos Disponíveis somados com o Valor Presente Atuarial dos Planos (Acumulado).

Os resultados apresentados nos Quadros 8 e 9 mostram que, comparativamente ao modelo previsto na IAS 26, em relação às demonstrações adotadas pelas EFPC no Brasil, não existem divergências em relação ao tipo de informação contida nas estruturas das demonstrações contábeis. 
Registra-se que no Brasil é comum encontrarmos nessas demonstrações de "contas" e "subcontas", diferentemente do proposto pela norma internacional.

Quadro 9 - Análise da Demonstração das Variações Patrimoniais Disponíveis para Benefício segundo o IAS 26.

\begin{tabular}{|c|c|c|}
\hline Itens da IAS 26 & $\begin{array}{c}\text { Demonstração das Obrigações } \\
\text { Atuariais do Plano de Benefícios - } \\
\text { DOAP (Padrão Brasileiro) }\end{array}$ & Observações \\
\hline $\begin{array}{l}\text { Valor Presente Atuarial dos } \\
\text { Benefícios do Plano }\end{array}$ & Não há divergências & $\begin{array}{l}\text { O valor presente Atuarial dos benefícios é } \\
\text { apresentado nas normas brasileiras como } \\
\text { Provisões Matemáticas a Constituir, que re- } \\
\text { presenta o total dos benefícios que serão pa- } \\
\text { gos pela entidade, ou seja, o valor atual do } \\
\text { fluxo projetado para o pagamento dos benefí- } \\
\text { cios futuros. }\end{array}$ \\
\hline $\begin{array}{l}\text { Excesso dos Ativos Disponíveis } \\
\text { somados com o Valor Presente } \\
\text { Atuarial dos Planos (Acumulado) }\end{array}$ & Não há divergências & $\begin{array}{l}\text { O excesso ou Superávit é demonstrado den- } \\
\text { tro do Equilíbrio técnico da DOAP. }\end{array}$ \\
\hline
\end{tabular}

Fonte: Elaboração Própria

Diante da análise efetuada, em resposta à questão da presente pesquisa, verifica-se que a estrutura dos elementos que compõem as demonstrações contábeis dos fundos de pensão do Brasil encontra-se, em sua maior parte, aderente ao disposto na IAS 26, sendo observadas, contudo, divergências de caráter formal na estrutura das demonstrações contábeis e na mensuração a valor justo dos investimentos, que são passíveis de serem alinhadas.

\section{CONSIDERAÇÕES FINAIS}

O presente estudo teve como objetivo verificar em que medida a elaboração das demonstrações contábeis das EFPC encontra-se aderente aos padrões contábeis internacionais, por meio de uma análise comparativa entre os elementos que compõem a estrutura da Demonstração da Mutação do Ativo Líquido (DMAL), da Demonstração do Ativo Líquido (DAL) e da Demonstração das Obrigações Atuariais do Plano de Benefícios (DOAP) definidos pelo padrão próprio brasileiro, e os elementos estabelecidos pela IAS 26 - Accounting and Reporting by Retirement Benefit Plans.

Com relação à estrutura das demonstrações contábeis, verificou-se que em essência a informação mínima exigida pela IAS 26 é cumprida totalmente pelas normas brasileiras adotadas para as EFPC. As diferenças observadas referem-se apenas à apresentação formal desses demonstrativos, tendo em vista a cultura do sistema previdenciário complementar fechado brasileiro, com relação aos critérios para registro e avaliação contábil de títulos e valores mobiliários das EFPC.

Sobre a análise da existência das contas presentes na Demonstração do Patrimônio Líquido Disponível para Benefícios, ou seja, a existência de Investimentos no valor justo, Passivos e Ativos Líquidos Disponíveis para benefícios, verificou-se que, em conformidade com a IAS 26, ao final da Demonstração do Ativo Líquido (DAL), é apresentada a informação do valor líquido do ativo que está disponível para o pagamento de benefícios.

Contudo, a DAL apresenta divergências quanto à exigência de que o valor do investimento deve ser apresentado a valor justo em sua carteira, pois dependendo da política de investimentos adotada por cada EFPC no Brasil, os investimentos podem ser mantidos até o vencimento ou a mercado, impactando a contabilização. Outra divergência se dá pelo fato de a DAL ser apresentada na forma de fluxo financeiro, não existindo a figura do passivo. Com isso, as obrigações do plano de benefícios, com relação ao ativo líquido disponível, são evidenciadas na forma de Obrigações Operacionais e Contingenciais.

Registra-se que, além das exigências da IAS 26, as normas brasileiras contemplam na DAL as Provisões Matemáticas (valor da variação das Reservas a Amortizar dos Planos de Benefícios), o 
Superávit/Déficit técnico (valor da variação patrimonial para cobertura dos compromissos dos Planos de Benefícios) e os Fundos Previdenciais (valor definido pelo atuário com o objetivo de cobertura dos riscos, oscilações de riscos ou mesmo para alocar recursos destinados a futuras alterações do Plano de Benefícios).

Com relação à Demonstração das Variações Patrimoniais Disponíveis para Benefício, apresentada pela IAS 26, não há divergências quando se compara o conteúdo da DMAL exigida pelo padrão brasileiro. $\mathrm{O}$ resultado dos investimentos, as contribuições para os planos de benefícios representa a adição do Ativo Líquido, contemplando o exigido pela IAS 26. Os benefícios concedidos e a conceder irá representar a destinação desses recursos, constituindo-se uma dedução dessas variações patrimoniais. Já na exigência da figura do "aumento do valor patrimonial”, a norma brasileira evidencia a variação na conta do Ativo Líquido do plano de benefícios, que é representado no patrimônio social ao final do exercício.

No caso da Demonstração do Patrimônio Líquido Disponível para Benefícios, também não se verifica divergências relevantes quando se compara com a DOAP exigida pelo padrão brasileiro com o disposto na IAS 26. Com relação a esse demonstrativo, verificou-se, também, que o modelo do balanço exigido pela IAS 26 contém uma pequena nota, que demonstra o valor presente atuarial disponível para os benefícios, distinguindo-se entre benefícios adquiridos e a adquirir. No modelo apresentado no Brasil, o valor presente atuarial dos benefícios é apresentado como Provisões Matemáticas a Constituir, que representa o total dos benefícios que serão pagos pela entidade, ou seja, o valor atual do fluxo projetado para o pagamento dos benefícios futuros, devendo essa exigência divulgada em quadro próprio.

Diante do exposto, verifica-se que a estrutura dos elementos que compõem as demonstrações contábeis dos fundos de pensão do Brasil encontra-se, em sua maior parte, aderente ao disposto na IAS 26, sendo observadas, contudo, divergências de caráter formal na estrutura das demonstrações contábeis e na mensuração a valor justo dos investimentos, passíveis de serem alinhadas.

\section{REFERÊNCIAS}

ALVES, D. S. Fundos de Pensão: Um Estudo Atuarial. 81 f. Monografia (Bacharelado em Estatística) - Universidade de Brasília, Brasília, 2011.

BRASIL. Ministério da Previdência Social. Secretaria de Políticas de Previdência Complementar. Fundos de Pensão: Coletânea de Normas. Brasília: SPPC, 2012.

CFC - CONSELHO FEDERAL DE CONTABILIDADE. Resolução CFC $n^{\circ}$ 1.272, de 22 de janeiro de 2010. Aprova a ITG 2001 - Entidade Fechada de Previdência Complementar. Disponível em: http://www.cfc.org.br/sisweb/sre/docs/RES 1272.doc. Acesso em: 20 ago. 2014.

COELHO, N. N. A.; CAMARGOS, M. A. Investimentos em previdência privada fechada: uma análise comparativa com outras opções de aplicações financeiras no Brasil. Revista Contemporânea de Economia e Gestão, V. 10, n. 2, p. 1-18, jul./dez 2012.

IFRS - INTERNATIONAL FINANCIAL ACCOUNTING REPORTING. IAS 26 Accounting and Reporting by Retirement Benefit Plans. 2012. Disponível em: http://www.ifrs.org/Documents/IAS26.pdf. Acesso em: 20 ago. 2014.

MATHEUS, F. C. M. A relação entre o plano REB e a queda nas adesões à FUNCEF. 147 f. Dissertação (Mestrado Profissional em Economia Aplicada à Gestão Previdenciária) - Faculdade de Economia, 
Administração, Contabilidade e Ciência da Informação e Documentação, Universidade de Brasília, Brasília, 2012.

MUTHUPANDIAN, K S: IAS 26 Accounting and Reporting by Retirement Benefit Plans - A Closer Look. The Management Accountant, v. 45, n. 2, p. 101-105, 2010.

TRINDADE, B. M. Contabilidade das Entidades Fechadas de Previdência Complementar: Implantação do Novo Plano de Contas. 2010. 